\title{
Burden, quality of life and distress of the main caregiver in head and neck, cervix and rectal cancer patients
}

\author{
Isália Miguel ${ }^{1, *}$, António Moreira ${ }^{1}$ and João Freire ${ }^{1}$ \\ ${ }^{1}$ Medical Oncology Department, Instituto Português de Oncologia de Lisboa Francisco Gentil, Rua Prof. Lima Basto, 1077-100, Lisboa, Portugal
}

\begin{abstract}
Purpose: Based on Portuguese experience, current practice does not focus sufficiently on the caregiver needs through caring of the cancer patient. Understanding the impact of different tumor types on caregiver burden, quality of life, and distress may help with organizing resources more efficiently to provide enhanced support for patients and caregivers. Methods: Ninety main caregivers of patients with cervix, rectal and head and neck cancer were interviewed at Instituto Português de Oncologia de Lisboa Francisco Gentil. The Portuguese versions of Zarit Burden Interview, Caregiver Quality of Life Index - Cancer (CQOLC) Scale and the distress thermometer were used. Results: The majority of caregivers were female (76.7\%), median age was 45.5years (20-79), 40\% were spouses and 38.7\% sons/daughters. Zarit Burden Interview average score was $25.2 \pm 11.6$, higher on head and neck cancer group. 59.5\% of caregivers had moderate burden and no cases of severe burden. Mean quality of life score was $64.8 \pm 15.8$ which was lower in the head and neck group. Average distress score across the three groups was seven and rectal group presented a lower score than the other two groups. A subgroup analysis (gender, kinship relation, employment status and cohabitation before starting care) of caregivers characteristics showed no statistical differences. Conclusion: There were little differences in the experience of caring within caregivers based on the three different cancer groups, although caregivers of patients with head and neck cancer scored consistently worse in the three scales studied. More efforts should be taken to optimize coping strategies for these caregivers, as well as non-cohabitant and active caregivers, who had a worse caring experience.
\end{abstract}

Keywords: caregiver; burden; quality of life, distress; cancer; palliative care

\section{Introduction}

Cancer patients undergo physical and psychological changes associated with the diagnosis, treatment and progression of disease. Caregivers have to face constant challenges, adjusting to the diagnosis, facing the need to support the patient, both emotionally and physically, as well as manage the daily routines [1]. As a result of dealing with the symptoms and behaviors of the patient, the caregiver may undergo a series of negative repercussions on their physical and mental health, but also on their domestic life, family and social relationships, which is usually referred as caregiver's burden [2]. In fact, caring for cancer patients interferes with quality of life (QoL) [3] and can produce an unpleasant experience of psychological (cognitive, behavioral, emotional), social and spiritual nature that can interfere with the ability to cope which is usually designed as distress [4]. The most important variables to predict which family member will become the main caregiver are patient's gender, cohabitation and kinship relation [5].

Based on the Portuguese experience, the current oncological practice does not focus sufficiently on the carer and its needs through the caring process of the cancer patient. The evaluation of the burden, QoL and distress of informal caregivers of cancer patients has been the subject of numerous studies in recent years aiming to provide the best possible support to the patient, the primary caregiver and the family throughout the disease trajectory. Understanding the impact on different tumor diagnosis on these variables may help organizing the existing resources more efficiently.

\footnotetext{
*Corresponding author: Isália Miguel, Medical Oncology Department, Instituto Português de Oncologia de Lisboa Francisco Gentil, Rua Prof. Lima Basto, 1077-100, Lisboa, Portugal. Tel.: 00351217229800 ; Fax: 00351217 229 880; Email: isaliamiguel@hotmail.com

Received 15 November 2016 Revised 28 January 2017 Accepted 15 February 2017 Published 22 February 2017

Citation: Miguel I, Moreira A, Freire J. Burden, quality of life and distress of the main caregiver in head and neck, cervix and rectum cancer patients. J Cancer Res Ther. 2017; 5(3):14-18. DOI: 10.14312/2052-4994.2017-3

Copyright: (C) 2017 Miguel I, et al. Published by NobleResearch Publishers This is an open-access article distributed under the terms of the Creative Commons Attribution License, which permits unrestricted use, distribution and reproduction in any medium, provided the original author and source are credited.
} 
We aim to assess the burden, QoL and distress of the primary informal caregiver of head and neck, cervix, and rectal cancer patients. These are three high prevalent groups of disease in our center and have a therapeutic approach that includes combination treatment with chemo-radiotherapy.

\section{Materials and methods}

\section{Subjects}

Main caregivers of patients with the diagnosis of cervical, rectal or headand neckcancer recruited ata multidisciplinary cancer center in Lisbon - Instituto Português de Oncologia de Lisboa Francisco Gentil - in 2013. Inclusion criteria for caregivers included: (a) residence time at home without regular working activity for more than three weeks; (b) age over 18 years old; (c) being able to read and write in the absence of overt cognitive impairment.

\section{Procedure}

This study was approved by the Ethical Committee of the Instituto Português de Oncologia de Lisboa Francisco Gentil. A personal interview with the main caregiver included: informed consent, a brief demographic and clinical survey including information on patient (age, gender, main diagnosis, treatment phase: curative/palliative) and caregiver (age, gender, relation to the patient, cohabitation with the patient, employment status), and three selfcompletion questionnaires to assess burden, QoL and distress. The validated Portuguese versions of the Zarit Burden Interview [6], the CQOLC scale [1] and the distress thermometer $[4,7]$ were used.

\section{Statistical analysis}

Descriptive and inferential analysis was performed with SPSS for Windows 17.0 (Chicago, IL). Continuous variables are presented as mean \pm standard deviation (SD) or median (minimum-maximum). Parametric tests (Student's t-test, Analysis of variance [ANOVA]) were used to test for differences between groups on demographic, clinical and scales scores. Categorical data is presented as percentage and frequency. In order to explore how different demographic characteristics affected caring we divided caregivers into two groups on four different variables: gender (male/female), kinship relation (spouse/other), cohabitation before start caring (yes/no), and employment status before starting care (active/non-active). Comparison between these groups was performed using Fisher and Chi-square tests. The significance level was set at $p<0.05$.

\section{Results}

\section{Sample characteristics}

The sample is composed of 90 caregivers, 30 in each cancer type group. Cancer patients were male in $53.3 \%$ with an unequal distribution in groups: cervical cancer - $0 \%$, rectal - $80 \%$ and head and neck - 80\%; median age was 62 years old $(26-81)$.

Despite the different gender distribution of cancer patients, there was a global majority of female caregivers (76.7\%), with a higher proportion of women caregivers in mainly male cancers: Rectal $-96.7 \%$ and head and neck $-86.7 \%$. Median age of caregivers was 45.5 years $(20-79)$.
In $40 \%$ of cases the main caregiver was the spouse. Half of the caregivers were employed and active before starting caregiving for the patient. The second most represented group of caregivers was offspring (37.8\%), mainly the patient's daughter (82.4\%). Other demographic data is shown in table 1.

\section{Burden assessment}

In 79 of 90 interviews (87.8\%) caregivers answered all items in the scale. The average score was $25.2 \pm 11.6$. Caregivers of patients with head and neck cancer scored higher than average (26.8 \pm 11.8 ) (Table 1).

More than half the caregivers (59.5\%) were in the moderate burden group (21 - 40 points), with no significant difference between the proportions found among the groups of cervical cancer, rectal and head and neck (66.7\%, 60\% and $76.7 \%$ respectively). No cases of severe burden were found.

ANOVA revealed significant differences in mean scale scores between cervix cancer caregivers and the other two groups just in item 13 of the scale ("Do you feel uncomfortable having your friends over because of your relative?", $p=0.028)$.

\section{Quality of life assessment}

In 65 of 90 interviews (72.2\%) caregivers answered all items in the CQOLC scale. Mean score was $64.8 \pm 15.8$. Caregivers of head and neck cancer patients generally scored lower in all items of the scale and had a lower total score, although not statistically significant (Table 1). In general, items related to emotional overload of the caregiver had the most weight on the final score value.

\section{Distress assessment}

Distress thermometer was answered on 82 occasions (91.1\%). Average score was 7, rectal cancer patients caregivers presented a lower score $(6.4 \pm 2.6)$ and cervix and head and neck cancer patients caregivers had a higher score (7.3) (Table 1).

On the problem list associated to this tool, the comparative analysis of positive responses revealed significant differences in self-reported "sadness" ( $p=0002)$, "concern" $(p=0.014)$, "cold sores" ( $p=0.015)$ and "sleep disorders" $(p=0.049)$, being more present in caregivers of head and neck cancer patients.

\section{Subgroup analysis}

In order to address how caring can affect different subgroups in our caregivers population, we conducted a subgroup comparison of the three scales scores taking into account four demographic characteristics of caregivers: gender, kinship relation, cohabitation and employment situation. Results are shown in table 2. No statistical differences were found.

\section{Discussion}

Each year the number of cancer patients increases in Portugal. Nowadays cancer has become a somehow chronic and progressive clinical disease, thus the affected 
Table 1 Main characteristics of caregivers and scale scores.

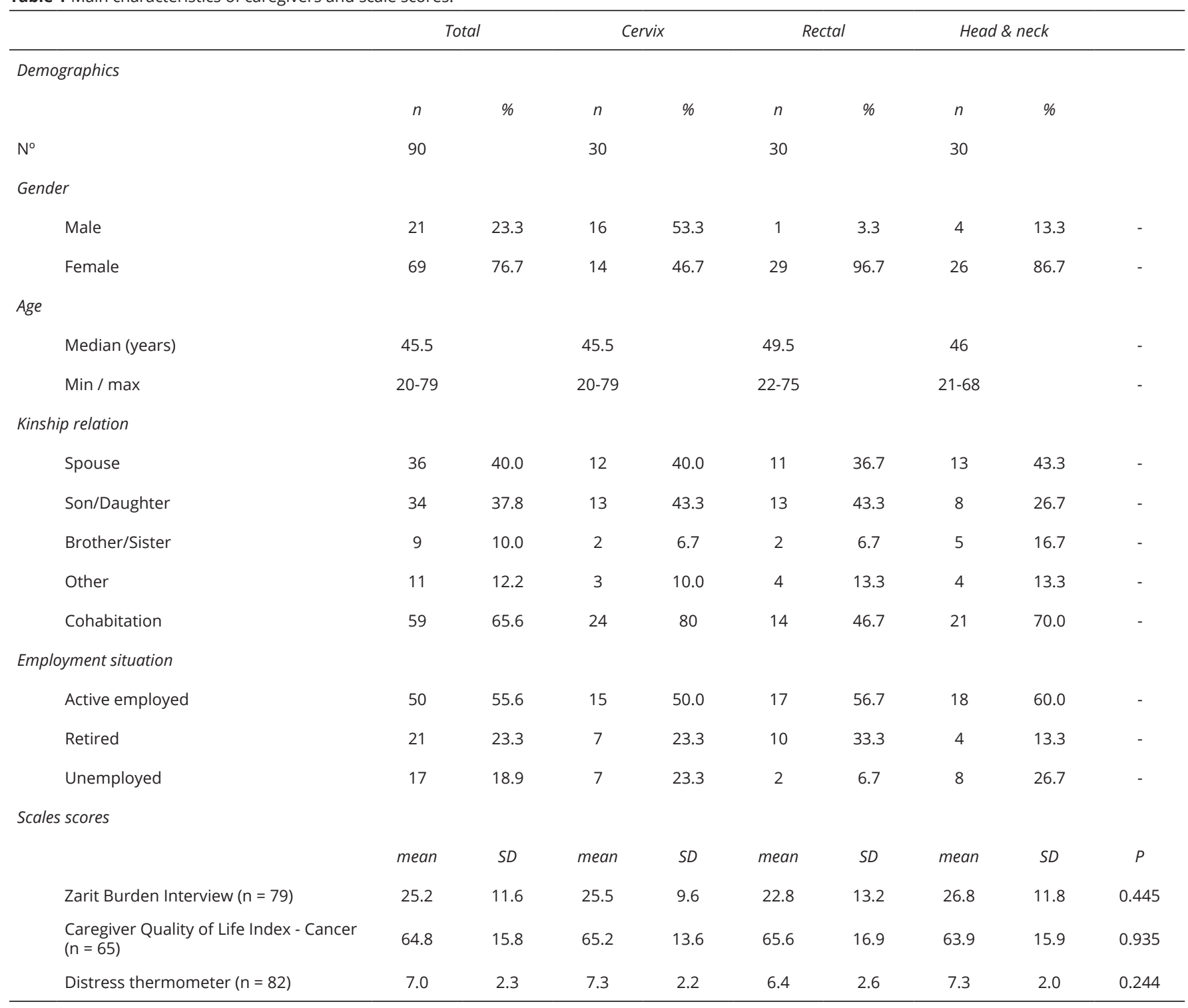

Table 2 Caregivers subgroups and mean scale scores ( \pm SD).

\begin{tabular}{|c|c|c|c|c|c|c|c|c|}
\hline & \multicolumn{2}{|c|}{ Gender } & \multicolumn{2}{|c|}{ Kinship relation } & \multicolumn{2}{|c|}{ Cohabitation } & \multicolumn{2}{|c|}{ Employment } \\
\hline & Male & Female & Spouse & Other & Yes & No & Active & Non-active \\
\hline \multicolumn{9}{|l|}{ Cervix cancer } \\
\hline Zarit Burden Interview & $24.3 \pm 8.8$ & $27.2 \pm 10.8$ & $23.3 \pm 9.0$ & $26.4 \pm 11.2$ & $24.8 \pm 9.5$ & $28.3 \pm 9.6$ & $26.6 \pm 11.2$ & $24.7 \pm 12.3$ \\
\hline CQOLC & $66.2 \pm 13.2$ & $63.8 \pm 13.2$ & $64.8 \pm 12.1$ & $65.5 \pm 15.1$ & $64.4 \pm 12.5$ & $69.0 \pm 19.5$ & $63.2 \pm 14.9$ & $66.7 \pm 12.8$ \\
\hline Distress thermometer & $6.9 \pm 2.5$ & $7.8 \pm 1.9$ & $7.7 \pm 1.7$ & $7.1 \pm 2.6$ & $7.3 \pm 2.0$ & $7.5 \pm 3.0$ & $7.2 \pm 2.3$ & $7.5 \pm 2.2$ \\
\hline \multicolumn{9}{|l|}{ Rectal cancer } \\
\hline Zarit Burden Interview & $24.0 \pm 0.0$ & $22.7 \pm 13.5$ & $19.2 \pm 14.2$ & $25.6 \pm 10.4$ & $17.6 \pm 13.3$ & $28.9 \pm 12.6$ & $23.5 \pm 12.7$ & $24.6 \pm 8.3$ \\
\hline CQOLC & $61.0 \pm 0.0$ & $65.8 \pm 13.2$ & $66.3 \pm 23.9$ & $65.2 \pm 16.4$ & $62.3 \pm 23.9$ & $65.2 \pm 16.4$ & $65.3 \pm 17.4$ & $66.0 \pm 21.9$ \\
\hline Distress thermometer & $7.0 \pm 0.0$ & $6.4 \pm 2.6$ & $6.8 \pm 2.8$ & $6.2 \pm 2.5$ & $6.7 \pm 2.7$ & $6.2 \pm 2.5$ & $5.9 \pm 2.6$ & $7.0 \pm 2.6$ \\
\hline \multicolumn{9}{|l|}{ Head \& neck cancer } \\
\hline Zarit Burden interview & $27.5 \pm 15.6$ & $26.7 \pm 11.5$ & $23.2 \pm 13.8$ & $29.8 \pm 9.2$ & $26.1 \pm 12.7$ & $28.3 \pm 9.4$ & $26.6 \pm 10.0$ & $27.1 \pm 14.4$ \\
\hline CQOLC & $62.5 \pm 12.0$ & $64.0 \pm 16.5$ & $67.1 \pm 13.9$ & $61.8 \pm 17.2$ & $64.6 \pm 18.0$ & $62.8 \pm 12.9$ & $63.2 \pm 11.1$ & $64.8 \pm 21.3$ \\
\hline Distress thermometer & $8.25 \pm 1.3$ & $7.1 \pm 2.1$ & $6.9 \pm 2.5$ & $7.5 \pm 1.6$ & $6.9 \pm 2.2$ & $8.1 \pm 1.3$ & $7.1 \pm 2.1$ & $7.6 \pm 1.8$ \\
\hline
\end{tabular}


population gradually loses independence, which increases the need to be looked after [8].

In our sample of caregivers there were a majority of females $(76.7 \%)$, with a higher proportion of women caregivers for patients with cancer of the rectum and head and neck, which are much more frequent in males. These data are consistent with other Portuguese studies, where women represented 63 to $81.7 \%[1,6]$. The median age of caregivers was lower than reported in other national and international studies $[1,9,10]$, which can be justified by the proportion of sons and daughters as caregivers compared to spouses (37.8\% and $40 \%$, respectively), higher than that found in those studies.

Caregiver burden was lower than reported in other studies based on caregiver of palliative care patients. Ferreira et al. described an average score of 37.3 in the Zarit scale in a sample of caregivers of palliative patients at home in Portugal [6]. However, a Canadian study of caregivers of women with breast cancer reported scores of 19.4 and 26.2 in the early phase and palliative treatment of disease, which are more in line with our study [11]. The caregivers of patients with head and neck cancer showed slightly higher burden scores, which can be explained by the fact that these patients often present mutilating consequences of cancer treatment and a deterioration of the general condition requiring greatest attention in their basic daily activities (hygiene, food, treatments, etc.). These caregivers have to endure the social stigma associated with head and neck patients and the numerous side effects of treatment [12], which implies more physical effort by the caregiver and greater time commitment that interferes with caregiver's expectations and creates in them a deep sense of patient dependence.

Caregivers of patients with cancer of head and neck showed also a QoL value below the average. Lee et al. evaluated the risk of depression and QoL of caregivers of head and neck patients, mostly at an early stage of the disease [12]. The results revealed a high level of depressive disorders and adaptation disorders, and these changes were associated with worse QoL.

A distress value over 4 is considered a reason for further evaluation $[13,14]$. In our sample this value was obtained in about $84.4 \%$ of caregivers, which can be considered a high distress level, and these patients were referred to social service for evaluation. Regarding the score in each group, it was higher in the group of cervical and head and neck cancer caregivers. Although, there are few studies on the distress in husband caregivers, it is known that men have more difficulty expressing their emotions and concerns, being common for husbands to feel powerless and deny their feelings [15]. It is described that in a couple where the woman has breast cancer, her husband suffers the anguish of decreased sexual function, unlike the ill wife, which focuses its attention on the sadness and despair of having cancer [16]. These may explain the higher results in the cervix cancer group, where the proportion of husbands was higher than in other groups. As for caregivers of patients with head and neck tumors, elevated levels of distress are described in the literature and several studies have shown that both patients and their caregivers have high levels of distress. Bard et al. describes distress levels higher in caregivers than in patients [17]. One reason given for this increase in distress is the progressive worsening of the general condition of the patient, with the consequent need for care and symptom control.

The main concerns in all groups of caregivers were related to emotional problems, in line with the results of the QoL scale, in which items of emotional overload contributed heavily to the score.

In the cervix cancer group of caregivers, which presents a more equitable distribution between genders, men presented lower burden, better QoL and less distress than women. This phenomenon has been described in other studies, and Lopez et al. consider that most of the questionnaires do not take into account the difficulties that men have to fully express their emotions [15], thus over representing their scores.

The worst scores in terms of burden and QoL were seen in the group of caregivers other than spouses (rectal and head and neck cancer) and non-cohabiting caregivers (in the three disease groups). Often, these caregivers did not experience so closely the evolution of the patient's condition and did not receive the same quality of information by health professionals. This may lead to an increased sense of loss of control and less coping strategies, resulting in an abrupt interruption of their life project. These caregivers must learn to reorganize their life facing this new situation, thus conducing to a deterioration of perceived QoL and distress, and higher caregiving burden [18].

Active, employed caregivers presented higher levels of burden (cervical and rectal cancer) and poorer QoL (in all groups). These results indicate that the fact of maintaining their jobs and taking care of a sick family member assumes a greater burden on these caregivers, resulting in difficulty to provide an adequate response to their own needs, leading to exhaustion and deteriorating QoL.

Limitations to this study include the absence of evaluation of the financial situation of caregivers and families as a possible contributing factor to burden, QoL and distress.

\section{Conclusions}

In general, we found little differences in the experience of caring for caregivers of three different cancer types, although caregivers of patients with head and neck cancer scored consistently higher in the three scales used to evaluate burden, QoL and distress. More efforts should be taken to optimize coping strategies in non-cohabitants and active caregivers, which may experience a worse life disruption feeling, underscoring the need for systematic evaluation and support to be provided through all the continuum of disease, not only in the palliative setting.

\section{Conflicts of interest}

Authors declare no conflicts of interest. 


\section{References}

[1] Santos C, Pais-Ribeiro JL, Lopes C. Estudo de Adaptação da Escala de Qualidade de Vida do Familiar/Cuidador do doente oncológico (CQOLC) [Adaptation study of the Caregiver Quality of Life IndexCancer (CQOLC) scale]. Rev Port Psicossomática. 2003; 5(1):105-118.

[2] Sequeira C. Adaptação e validação da escala de sobrecarga do cuidador de Zarit [Adaptation and validation of The Zarit Burden Interview]. Rev Referência. 2010; 2(12):9-16.

[3] Pais-Ribeiro, J.L. Qualidade de vida e doença oncológica [Quality of life and oncological disease]. In: Dias MR, Durá E. Territórios da Psicologia Oncológica. Lisboa: Climepsi Editores; 2002.

[4] National Comprehensive Cancer Network. Distress Management Clinical Practice Guidelines in Oncology. 2008.

[5] García-Maldonado G, Saldívar-González AH, Martínez-Perales GM, Sánchez-Nuncio R, Lin-Ochoa D. Sobrecarga emocional en cuidadores de mujeres que requieren cuidados paliativos [Emotional overload in caretakers of women requiring palliative care]. Rev Med Hosp Gen Mex. 2012; 75(3):140-147.

[6] Ferreira F, Pinto A, Laranjeira A, Pinto AC, Lopes A, et al. Validação da escala de Zarit: sobrecarga do cuidador em cuidados paliativos domiciliários, para população portuguesa [Validation of the Zarit's scale ("Zarit Burden Interview") for the portuguese population in the field of domiciliary palliative patient care]. Cadernos de Saúde. 2010; 3(2):13-19.

[7] Bacalhau R. Termômetro de Distress [Distress thermomether]. In: Instituto Português de Oncologia Lisboa Francisco Gentil. 2004.

[8] Barron B, Alvarado S. Desgaste Físico y Emocional del Cuidador Primario en cáncer [Physical and Emotional Wear of the Primary Caregiver on Cancer]. Cancerologia. 2009; 4(1):39-46.

[9] Thomas C, Morris SM, Harman J. Companions thorugh cancer: the care given by informal carers in cancer contexts. Soc Sci Med. 2002; 54(4):529-544.

[10] Hanly P, Céilleachair AÓ, Skally M, O'Leary E, Kapur K, et al. How much does it cost to care for surivors of coloretal cancer? Caregivers's time, travel and out-of-pocket costs. Support Care Cancer. 2013; 21(9):25832592.

[11] Grunfeld E, Coyle D, Whelan T, Clinch J, Reyno L, et al. Family caregiver burden: results of a longitudinal study of breast cancer patients and their principal caregivers. CMAJ. 2004; 170(12):1795-1801.

[12] Lee $Y$, Lin PY, Chien CY, Fang FM. Prevalence and risk factors of depressive disorder in caregivers of patients with head and neck cancer. Phychooncology. 2015; 24(2):155-1561.

[13] Jacobsen PB, Donovan KA, Trask PC, Fleishman SB, Zabora J, et al. Screening for psychologic distress in ambulatory cancer patients. Cancer. 2005; 103(7):1494-1502.

[14] Mitchell AJ. Pooled results from 38 analyses of the accuracy of distress thermometer and other ultra-short methods of detecting cancerrelated mood disorders. J Clin Oncol. 2008; 25(29):4670-4681.

[15] Lopez V, Copp G, Molassiotis A. Male Caregivers of patients with breast and gynecologic cancer. Cancer Nurs. 2012; 35(6):402-410.

[16] Bloch S, Love A, Macvean M, Duchesne G, Couper J, Kissane D. Psychological adjustment of men with prostate cancer: A review of the literature. Biopsychosoc Med. 2007; 1:2.

[17] Badr H, Gupta V, Sikora A, Posner M. Psychological distress in patients and caregivers over the course of radiotherapy for head and neck cancer. Oral Oncol. 2014; 50(10):1005-1011.

[18] Expósito Y. La calidad de vida en los cuidadores primarios de pacientes con cáncer [Quality of life in primary caregivers of cancer patients]. Rev Haban Cienc Med [Internet]. 2008; 7(3). 